\title{
Gender and occupational wage gaps in Romania: from planned equality to market inequality?
}

\author{
Daniela Andrén ${ }^{1 *}$ and Thomas Andrén ${ }^{2}$
}

\author{
* Correspondence: \\ Daniela.Andren@oru.se \\ ${ }^{1}$ Örebro University School of \\ Business, Örebro SE-701 82, Sweden \\ Full list of author information is \\ available at the end of the article
}

\begin{abstract}
In Romania, the communist regime promoted an official policy of gender equality for more than 40 years, providing equal access to education and employment and restricting pay differentiation based on gender. After its fall in December 1989, the promotion of equal opportunities and treatment for men and women did not constitute a priority for any governments of the 1990s. This paper analyzes both gender and occupational wage gaps before and during the first years of the transition to a market economy and finds that the communist institutions did succeed in eliminating the gender wage differences in female- and male-dominated occupations but not in gender-integrated occupations. During both regimes, wage differences were, in general, much higher among workers of the same gender working in different occupations than between men and women working in the same occupational group, and women experienced a larger variation in occupational wage differentials than men.
\end{abstract}

JEL codes: J24; J31; J71; J78; P26; P27

Keywords: Romania; Transition; Female- and male-dominated occupations; Gender wage gap; Occupational wage gap

\section{Introduction}

The communist regimes in Eastern Europe institutionalized the principle of "equal pay for equal work" and used centralized wage grids for wage-setting on the labor market several decades before their fall in the beginning of the 1990s. Consequently, the wage structure was identical for all workers in general and for men and women in particular. Therefore, no wage discrimination based on gender should have existed during the communist era.

In contrast, the transition from a centrally planned economy to a market economy resulted in a substantial and rapid change in the wage structure. Returns to both measured skills (education, occupation) and unmeasured skills increased, and older workers and women appear to be the groups that lost most from the transition (Brainerd 2000). This opens up the question of whether the "planned equality" transformed into a "market inequality" during the transition years. This paper attempts to answer this question using data from cross-sectional household surveys conducted during the transition years in Romania. The data provide unique retrospective information about starting wages and occupations since 1960s.

(c) 2015 Andrén and Andrén; licensee Springer. This is an Open Access article distributed under the terms of the Creative Commons Attribution License (http://creativecommons.org/licenses/by/4.0), which permits unrestricted use, distribution, and reproduction in any medium, provided the original work is properly credited. 
The relatively rich literature on wage gaps in transition economies has reported that the gender wage gap decreased during the first years of transition, ${ }^{1}$ and it has been relatively stable through the 1990s in several transition economies (Newell and Reilly 2000). The pattern of the high concentration of women in occupations situated in the lower part of the wage distribution had direct consequences for the gender wage gap. The gender wage gap was also affected by changes in the overall wage distribution (Brainerd 2000), the drop in the employment of low-wage female earners (Hunt 2002), and the expansion of the high-wage service sector (Giddings 2002), which was typically female-dominated before the transition. However, occupational segregation is not always to blame for most of the gender wage gap; rather, the gap is mostly a withinoccupation, within-establishment phenomenon (Jurajda 2003, 2005).

The only two studies of the gender wage gap in Romania during the first years of the transition (e.g., Paternostro and Sahn 1999; Skoufias 2003) reported results similar to those of studies that used data from other socialist countries of Central and Eastern Europe: The gender wage gap generally diminishes in the transition process.

A few studies that analyze data a few years before the communist regimes' fall reported that the gender wage gap existed and was explained by occupational attainment (e.g., Brainerd 2000, Giddings 2002 and Orazem and Vodopivec 2000). Atkinson and Micklewright (1992) reported that the gender wage gap was substantial under communism given the low wage dispersion. Ham et al. (1995) reported that the gender wage gap is generally attributed to discriminatory promotion practices and to the segregation of women into low-paying occupations. To our knowledge, no study has analyzed the occupational wage gap either in general or separately for men and women before and after the fall of the communist regime.

The contribution of this paper to the existing literature on the wage gap in transition countries is threefold. First, we analyze the gender wage gap in Romania over almost four decades of the communist regime and during the transition period, up to $2000{ }^{2}$ Second, we analyze the occupational wage gap in general and separately for men and women. Third, in the empirical analysis, we use a structural approach that integrates the occupational attainment and stratification for men and women and aspects of the institutional settings.

We analyze the gender wage gap in Romania during the centrally planned period with a follow-up period during the transition towards a market economy. The centralized wage-setting process in Romania during the communist regime did, in fact, follow a standard set of rules based on industry, occupation, education level and length of service. Because men worked more often in heavy industries, where occupations were associated with higher risk and higher wages, and women worked more often in education and healthcare sectors, where wages were, on average, lower, a wage gap between men and women did, in effect, exist during these years. However, with no wage discrimination in place, the wage gap between men and women should largely be explained by occupation.

After the fall of communism in 1991, a new wage law formally decentralized wage determination, prices were liberalized, and the process of the mass privatization of state-owned enterprises began. Labor force participation is decreasing considerably for both men and women, and wage structure is being determined autonomously through collective or individual negotiations between employees and employers. 
Our paper has three main hypotheses: 1) If solidarity wage bargaining was effective in promoting equal pay for equal job types, then controlling for job characteristics should generate an adjusted wage gap of zero; 2) the process of labor reallocation caused by the economic transition had an effect not only on the occupational distribution of men and women but also on the gender wage gap; and 3) the process of labor reallocation also had an effect on the occupational wage gap in general and for men and women separately.

The analysis is based on data drawn from the Romanian Integrated Household Survey, which includes a representative sample for each year. For the socialist years, 1960-1989, we use retrospective information from the 1994 survey, and for the analyzed transition years, we use the annual household survey (1994, 1996, 1998, and 2000). Except for Münich et al. (2005), who estimate returns to human capital for men in the Czech Republic during the communist period 1948-1989 and the transition period 1991-1996, no other data set provides information on individuals for such long periods of time during communism.

We find that in Romania, the average female worker earned approximately $72 \%$ of the mean male wage during the communist era, but contrary to previous studies, this observed gender wage gap remained almost constant over time. However, the relative importance of the individual components of the wage decomposition varies across years, with much higher variations in both female-dominated and male-dominated occupations during the transition period. Our results support our hypotheses that 1) there was a gender wage gap during the communist regime; 2) the occupational attainment explained a large part of the gender wage gap; and 3) there are differences in the occupational wage gap between men and women during the years of the planned economy and the market economy.

The paper will proceed with Section 2, which briefly explains some institutional aspects of Romania during the communist regime and the transition period. Section 3 outlines the empirical specification. The data and the samples used in the paper are presented in Section 4, and the results are presented in Section 5. Section 6 summarizes the paper and discusses policy implications.

\section{Human capital and wage formation in Romania}

In Romania, the communist regime proclaimed from its establishment in the middle of the 1940s that liberty, gender equality and the emancipation of women were some of the main targets in the development of the new socialist society. A nationwide campaign was launched to eliminate female illiteracy, to increase the enrollment of women in secondary schools and universities, and to increase female employment outside of the household. Before the communist regime's fall in 1989, the official statistics show a) a relatively high and gender-neutral proportion of young people who were enrolled in high schools or universities: Approximately 70\% of males aged 1519 years and approximately $72 \%$ of females of the same age were enrolled in high schools, and approximately 6\% of both males and females aged 19-25 years were enrolled in some form of higher education (National Commission for Statistics 1995); b) the literacy rates were $95.6 \%$ for women and 98.6\% for men (UNESCO 2002); and c) the workforce participation rates were high relative to Western standards for both women (approximately 90-95\%) and men (approximately 100 percent).

During the communist regime's years, all citizens of working-age who had a work capacity had the right and duty to work and were guaranteed a job, but labor markets 
were subject to several constraints, including the strict regulation of mobility, the central allocation of university graduates to jobs, and a centralized wage-setting process with a standard set of rules based on industry, occupation, and length of service. Wages were set according to industry-specific wage grids and varied only with the difficulty of the job and with the worker's education and work experience but not with gender. After the fall of communism in December 1989, the new wage law of February 1991 formally decentralized wage determination in Romania. All state and privately owned commercial companies were granted the right to determine their wage structure autonomously through collective or individual negotiations between employees and employers. All restrictions on eligibility for promotion, bonuses, and internal and external migration were lifted. Additionally, the hours of work per week were reduced from 46 to 40 without any decrease in monthly wages (Skoufias 2003).

The structural starting point of the economic transformation was an oversized stateowned industry characterized by low competition and weak interaction with the world market. Despite still being the majority owner, the state intervention had been limited to periodic wage indexations only for state institutions to diminish the increasing gap caused by more rapid wage increases in some industries because of the negotiations of collective and individual contracts. The wage setting, supplemented by price liberalization and privatization and a lack of (the enforcement of) laws had an effect on labor market participation (Earle and Sapatoru 1993), occupational attainment and, nonetheless, on people's opinion about their opportunities and their place on the labor market. On the 2000 Gender Barometer, about half of the interviewees answered that real equality of rights between men and women does not exist. ${ }^{3}$ The majority (75-88\%) considered gender not to be important in some occupations with respect to whom should be employed (e.g., media, nongovernmental organizations, public administration, health, agriculture and banking) but that men should be employed in mining and metallurgy and construction, and women should be employed in the textile industry.

\section{Empirical framework}

Several papers have analyzed occupational segregation and wages by estimating the effect of women's density in different occupations on individual wages. A potential problem in these studies is the endogeneity of occupational choice. Except for a few studies that do take this problem into account, ${ }^{4}$ most of the literature is based on the assumption that occupational attainment is exogenous. To analyze the gender wage gap within and between occupational groups, we chose to formulate a selection model with an endogenous switch among three broad types of occupational groups. We therefore specify a separate wage equation for each occupational group that will be estimated for both men and women separately:

$$
\begin{aligned}
& Y_{1}=X \beta_{1}+U_{1} \text { male-dominated }(\mathrm{MD}) \text { occupations, } \\
& Y_{2}=X \beta_{2}+U_{2} \text { gender-integrated }(\mathrm{GI}) \text { occupations, } \\
& Y_{3}=X \beta_{3}+U_{3} \text { female-dominated }(\mathrm{FD}) \text { occupations, }
\end{aligned}
$$

where $Y j$ represents the market wage (in a logarithmic form) for a given individual in occupational group $j, j=1,2$ or 3 ; group 1 represents male-dominated (MD) 
occupations, group 2 represents gender-integrated (GI) occupations, and group 3 represents female-dominated (FD) occupations. $X$ is a matrix with explanatory variables associated with the market wage, and $\beta_{j}$ is the corresponding parameter vector, which is unique for each occupational group.

The occupational choice is based on taste or the propensity for a specific occupation, which is located in one of the predefined occupational groups. The choice mechanism for the individual is specified as a linear latent variable model:

$$
D^{*}=Z \gamma+\varepsilon
$$

where $Z$ is a matrix with explanatory variables associated with the occupational propensity score, and $\gamma$ is the corresponding parameter vector for these variables. The dependent latent variable $D^{*}$ represents the propensity to choose a male-dominated occupation. A low value of $D^{*}$ represents a low propensity to choose a male dominated occupation, which should be seen as equivalent to a high propensity to choose a female-dominated occupation. If the latent variable takes a value between a high and a low value, the individual will choose an occupation from the gender-integrated group. ${ }^{5}$

The parameter estimates from the model are used to compute the components of the gender wage gap for the entire sample (i.e., all occupations together) and for occupational groups (i.e., MD, GI and FD occupations) and to compute the occupational wage gap for men and women separately. ${ }^{6}$

The nature of the model allows us to decompose the total wage gap into four mutually exclusive components. The first component is related to endowments and is based on differences in observables such as age and education. The second component (the occupational effect) is related to the differences between men and women in both the structure of occupational attainment and their qualifications for the chosen occupation. The third component (the selectivity effect) is related to the self selection into occupations that is driven by unobservables. Because the occupational choice is made on the basis of individuals' preferences, skills, or abilities related to different work tasks, this choice could potentially affect the wages positively under the assumption that strong preferences and productivity have a positive association. If the mean selection effect for men is stronger than that for women, the total effect will be positive. However, if the sorting into different occupational groups is random, the effect will be zero. The fourth component is related to differences in return to observables between men and women. In a situation with no discrimination, this component will be zero. However, it is important to recognize that a non-zero effect also could be a result of not controlling for all relevant variables. The fourth component is therefore referred to as the unexplained effect.

The advantage of this approach is that it allows us not only to estimate the wage effect of female density in any given occupation but also to estimate the unexplained gender wage gap within a given occupation and how this gap varies across occupational groups. In addition, it is possible to test whether the returns to endowments differ across both gender and occupations. However, there are at least two problems with this approach: 1) finding valid instruments for occupational choices to secure identification and 2) the accuracy of the occupational aggregation. Concerning the first problem, it is generally difficult to obtain observable characteristics that influence occupational choice but not wages. Our attempt to address this issue will be discussed and motivated in the data section below. In regard to the aggregation of occupation choices, we chose 
to follow the previous literature for comparability reasons ${ }^{7}$ and aggregate along three broad categories, as described above.

\section{Data}

The data used in the empirical analysis are drawn from the Romanian Integrated Household Survey (RIHS). For the socialist years, 1960-1989, we use retrospective information from the 1994 survey, and for the analyzed transition years, we use the annual household survey $\left(1994,1996,1998\right.$, and 2000). ${ }^{8}$ The number of observations that include information about the wages and explanatory variables relevant for analysis vary across the cross-sections, starting at 25,565 in 1994, decreasing to 21,518 in 1998 , and decreasing to 17,480 in 2000 . The historical labor force data provide information on starting wages and occupation for approximately 12,000 individuals.

The net monthly wage is computed as earnings on the primary job in the previous month minus taxes and other mandatory contributions. The wage variable refers to the previous month from 1994 to 2000 and to the starting wage from 1960 to 1989 . The rankings of different industries were stable over time, but there is a degree of variation in the magnitude of wage differentials among occupations during transition years, when certain industries pay all types of workers high wages (e.g., the banks) and others pay all types of workers relatively low wages. However, the wage structure has been remarkably stable during the communist era, and therefore the starting wages can be used from 1950 to 1989. Our concerns are gender and occupational wage gaps rather than the overall level of real wages, so our approach to estimating repeated cross-sections involves no deflation of the dependent variable. Nevertheless, the significant inflation during the 1990s requires some within-survey period adjustments, for which we use monthly dummies. The evolution of women's net monthly wages relative to men's varied between $84 \%$ in $1971-75$ and $91 \%$ during 1986-89 (Figure 1). Compared to the female-male wage ratio reported by Brainerd (2000), the Romanian values were close to those in Columbia (85\% in 1988) and Sweden (84\% in 1992) but higher than those in the USA (70\% in 1987) and the Russian Republic (69\% in 1989).

The next important variable in our analysis is occupation. Using a conventional approach that sorts occupations into three groups based on the proportion of female workers in the occupation, ${ }^{9}$ we define occupations with less than $33 \%$ women as being male-dominated and occupations with more than $67 \%$ women as being femaledominated. The remaining occupations are referred to as gender integrated. ${ }^{10}$ The highest difference in wages between men and women was in the gender-integrated group; the women's net monthly wages were approximately $80 \%$ those of the men's during the transition years. The smallest difference was in the female-dominated group, where women earned, on average, approximately 90-95\% of men's monthly wages from 1981-1996 (Figure 1).

In the period before 1989, the relative differences in the net monthly wages among the three occupational groups suggest that there was a moving trend towards the equalization of occupational wage differences for both men and women (Figure 2). Regardless of their gender, people working in male-dominated occupations earned more than people working in gender-integrated occupations, but this relationship switched directions after 1994 and increased again in 1996 and 1997. Furthermore, the 


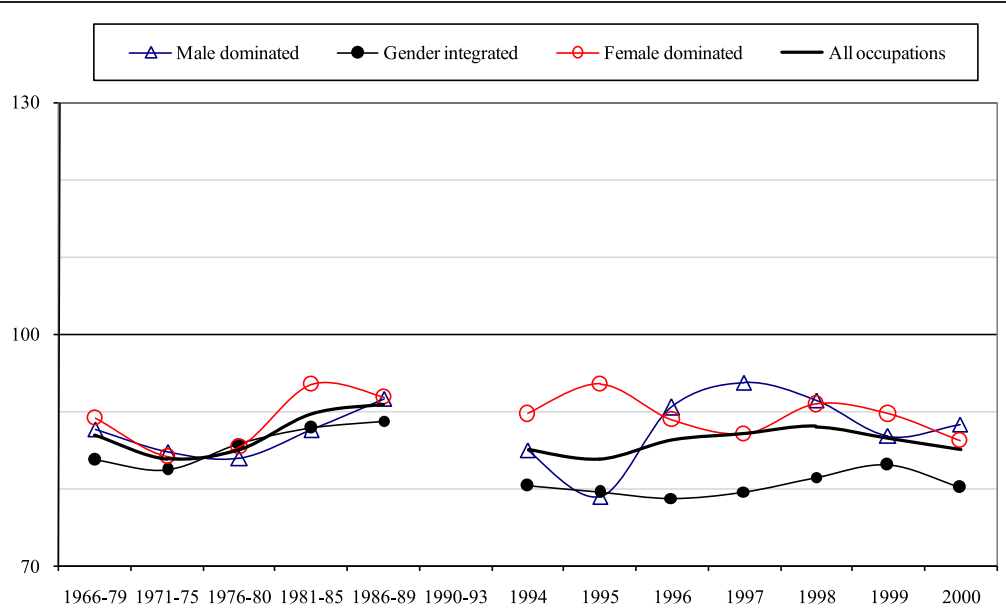

Figure 1 The women's monthly net wages relative to men's (in \%).

evolution of the relative differences in the occupational wage gap during the transition years was different for men and women, suggesting that market mechanisms can generate occupational wage differences. The occupational wage differences were larger for women than for men after 1994. For men, there was basically no difference between gender-integrated and female-dominated occupations, whereas women working in the
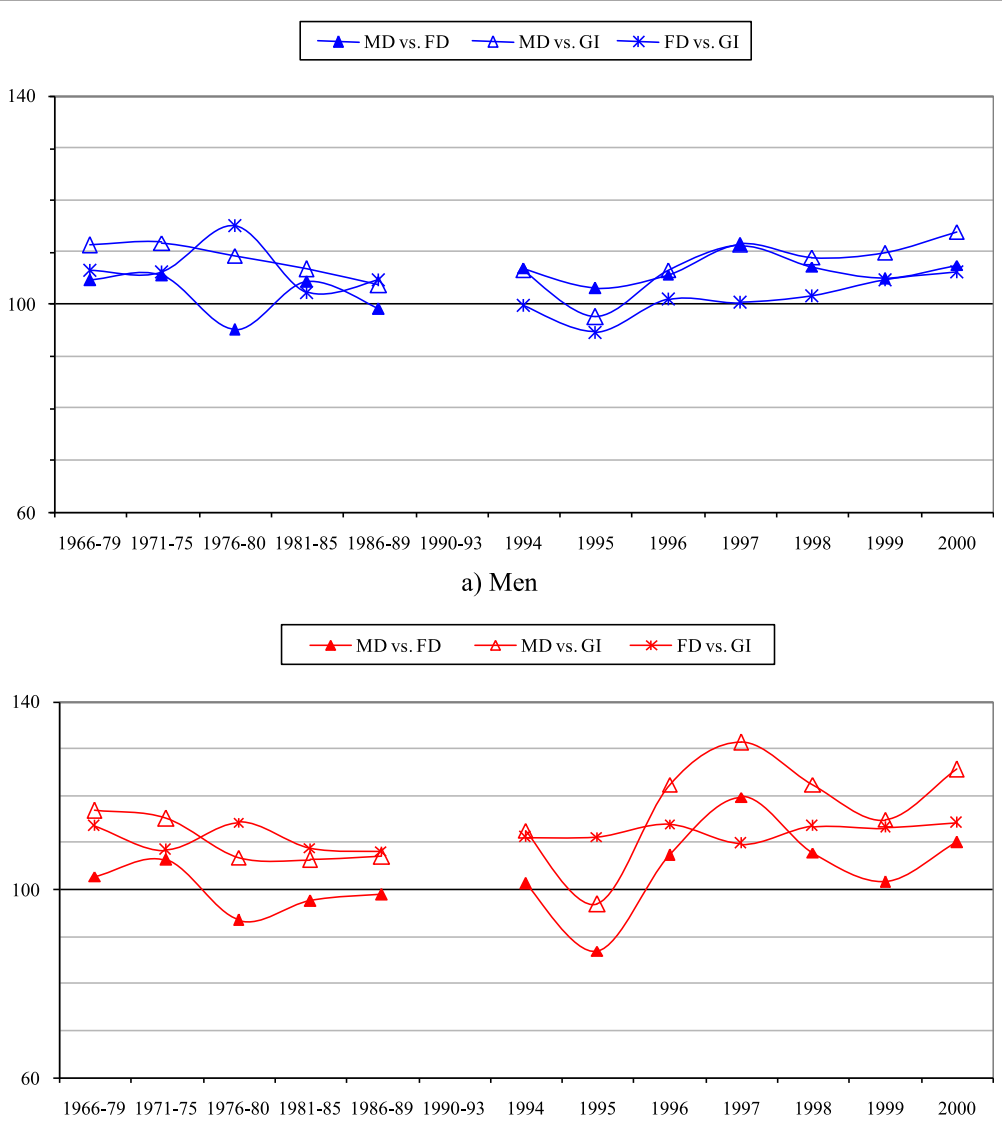

b) Women

Figure $\mathbf{2}$ The relative monthly net wages between occupations (in \%) by gender. 
group of female-dominated occupations earned less than women working in the group of gender-integrated occupations.

Another group of variables important in analyzing the effect of occupational selection on domain-specific wages were the instruments for occupational choices. It is generally difficult to obtain observable characteristics that influence occupational choice but not wages. Using data for several years characterized by different structural changes in the economy makes it even harder to find instruments that work well for both men and women for all years. However, the institutional settings during the analyzed period suggest that the wage differentiation based on gender was restricted under central planning and even in the beginning of the transition period. Wages were set according to industry-specific wage grids and varied only with the difficulty of the job and with workers' education and experience, not with gender. Additionally, under the central plan, given their last completed level of education and their ranking (based on the academic grades and political, cultural and even sportive involvement), people could choose from a given and very limited list of jobs. Therefore, we argue that the last completed level of schooling is an exogenous source of variation in occupational attainment that allows us to identify the causal effect of occupation. More exactly, after finishing compulsory education (i.e., 8 years of schooling), people had to pass an admissions test to continue their education at the high school level. A majority of those who did not pass the test instead continued into vocational schools (Most of the time, vocational programs lasted 1-2 years at the workplace). Those who passed the test were admitted to high school (lyceums), which could be general (e.g., mathematics-physics, natural sciences, and philosophy-history), specialized (e.g., economics, pedagogy, health care, and art), industrial or agro-industrial. After two years of high school, students had to pass a new test to continue the last two years of high school. When finishing these two additional years, students had to pass another set of tests to receive a high school diploma. Only people who had a high school diploma could then take the university admissions test (University education was 3-6 years). High school graduates who were not admitted to a university usually did not have many occupational choices; only a few (usually those who graduated from a specialized high school) had a specific context for their occupation (e.g., nurses or teachers in pre-school and primary education). Of those who were not admitted to a university, graduates from general high schools had, on average, better academic merits and human capital than their peers who had graduated from industrial and agro-industrial high schools, but there were no clear rules for who would get the most attractive job. Sometimes, they had to compete even with their peers who graduated from a shorter vocational program (from vocational schools). These are some of the institutional settings that suggest that wages were related to occupation based on a combination of factors, such as education, job, and task-specific requirements during the analyzed years (both before 1989 and in the first years of the transition). Due to this combination, it happened that people in different occupations with different levels of education but different working conditions had almost the same salary.

Hence, to control for the effect of education on wages and occupational attainment, respectively, we use two different groups of education dummies. The first group, used in the wage equations, includes three variables for education level: lower, medium and higher. The second group, used in the selection equation, includes five variables for 
human capital specialization: compulsory, vocational, 2 or 4 years of high school, posthigh school, and university. The "lower" category in the wage equation covers "compulsory" (which can be 4 or 8 years) and "vocational" in the selection equation, whereas "medium" covers "high school" and "post-high school"; and "higher" is the same as "university." Due to these differences, we use "vocational", "2 or 4 years of high school", and "post high school" as instruments. In addition to these instruments, we use three region dummies that control for occupational "specialization" within ethnic groups [(Borjas (1992, 1995) and Lehrer (2004)]. We control for this effect through geographical regions. Following the same strategy as for education, the regions are aggregated in different groups of dummies: (i) four dummies for the richest geographical regions (R4R8), in the wage equations; and (ii) five dummies for regions with a large majority of ethnic Romanians (R1-R4 and R8) in comparison with the regions with a relatively high proportion ethnic Hungarians, ${ }^{11}$ in the selection equation. Although our instrumental variables are significantly correlated with the occupation, we are aware of our limited theoretical considerations and intuition to support the validity condition. Therefore, we suggest that our results should be interpreted with caution.

\section{Results}

We estimate a selection model with an endogenous switch among three broad types of occupational groups defined by their gender composition: male-dominated, genderintegrated, and female-dominated occupations. The parameters for the occupational selection equation and the domain-specific wage equations are estimated simultaneously.

\subsection{Selection into occupational groups}

The parameters for the occupational selection equation and the domain-specific wage equations are estimated simultaneously. Table 1 presents the estimates of the selection equations for men and women, respectively. ${ }^{12}$

Additionally, Table 1 presents the estimated variances and covariances of the error terms of the wage and selection equations, which provide useful information regarding the sorting behavior of individuals across groups. The estimated coefficients of the occupational selection (or attainment) equation indicate that the probability of working in a given occupational group (i.e., MD, GI or FD) differs between men and women. Although it is not possible to pinpoint a clear trend, the parameters suggest that men's preferences for a given occupation were more stable than women's. Women's correlations between observables and occupational choice are less stable over time. However, when these correlations are statistically significant, they suggest that women changed their preferences during the transition years. The differences between men and women during the communist era might be due to the big changes in the economy during that time (such as industrialization, the mass privatization of agriculture, and the prohibition of abortion), and the differences during the transition years might indicate the collapse of the socialist support for women but also the changes in the economy and society, which might have changed women's work preferences and/or opportunities. However, the covariances for 2000 are positive for both men and women, indicating a negative selection effect for people who chose to work in male-dominated occupations and a positive selection effect for those who worked in female-dominated occupations. 
Table 1 Selection equation estimates, by gender, 1960-2000

\begin{tabular}{|c|c|c|c|c|c|c|c|c|c|c|c|c|c|c|c|c|c|c|c|c|}
\hline & \multicolumn{10}{|l|}{ Women } & \multicolumn{10}{|l|}{ Men } \\
\hline & $1960-$ & 89 & 1994 & & 1996 & & 1998 & & 2000 & & $1960-$ & 89 & 1994 & & 1996 & & 1998 & & 2000 & \\
\hline$\overline{c_{1}}$ & -0.894 & $* * *$ & -0.510 & ** & -1.072 & $* * *$ & -1.345 & $* * *$ & -0.682 & ** & -1.285 & $* * *$ & -0.938 & $* * *$ & -0.544 & $* * *$ & -0.610 & $* * *$ & -0.754 & $* * *$ \\
\hline $\mathrm{C}_{2}$ & 2.138 & $* * *$ & 2.112 & $* * *$ & 1.658 & $* * *$ & 1.547 & $* * *$ & 2.149 & $* * *$ & 1.595 & $* * *$ & 1.698 & $* * *$ & 2.174 & $* * *$ & 2.214 & $* * *$ & 1.931 & $* * *$ \\
\hline Age & 0.425 & $* * *$ & 0.365 & $* * *$ & 0.004 & & 0.000 & & 0.274 & * & -0.119 & & -0.303 & $* * *$ & -0.008 & & 0.029 & & -0.009 & \\
\hline $\mathrm{Age}^{2} / 10$ & -0.049 & $* *$ & -0.034 & $* *$ & 0.014 & & 0.005 & & -0.024 & & 0.026 & & 0.048 & $* * *$ & 0.007 & & 0.003 & & 0.012 & \\
\hline \multicolumn{21}{|l|}{ Educational Level1) } \\
\hline Vocational & 0.113 & $*$ & 0.222 & $* * *$ & 0.219 & $* * *$ & 0.253 & $* * *$ & 0.182 & $* * *$ & -0.128 & $* *$ & 0.155 & $* * *$ & 0.105 & $* * *$ & 0.097 & $* * *$ & -0.255 & $* * *$ \\
\hline High school 2 years ${ }^{\#}$ & 0.766 & *** & 0.802 & $* * *$ & 0.173 & $* * *$ & 0.226 & $* * *$ & 0.273 & $* * *$ & 0.208 & $* * *$ & 0.372 & $* * *$ & 0.034 & & 0.139 & $* * *$ & -0.172 & $* * *$ \\
\hline High school 4 years & & & & & 0.934 & $* * *$ & 0.975 & $* * *$ & 0.932 & $* * *$ & & & & & 0.403 & $* * *$ & 0.421 & $* * *$ & -0.017 & \\
\hline After high school & 0.922 & *** & 0.718 & $* * *$ & 0.805 & $* * *$ & 1.066 & $* * *$ & 1.033 & $* * *$ & 0.719 & $* * *$ & 0.689 & $* * *$ & 0.634 & $* * *$ & 0.652 & $* * *$ & -0.546 & $* * *$ \\
\hline University & 0.163 & & 0.159 & $* * *$ & 0.296 & $* * *$ & 0.347 & $* * *$ & 0.343 & $* * *$ & 0.076 & & 0.470 & $* * *$ & 0.381 & $* * *$ & 0.466 & $* * *$ & 0.065 & \\
\hline \multicolumn{21}{|l|}{ Region } \\
\hline R1: North-East & -0.101 & $*$ & -0.174 & $* * *$ & -0.185 & $* * *$ & -0.240 & $* * *$ & -0.173 & $* * *$ & -0.010 & & -0.107 & $* * *$ & -0.182 & $* * *$ & -0.151 & $* * *$ & 0.033 & \\
\hline R2: South-East & -0.067 & & -0.008 & & -0.087 & $* *$ & -0.151 & $* * *$ & -0.101 & $* *$ & -0.277 & $* * *$ & 0.047 & & -0.047 & & -0.110 & $* * *$ & -0.183 & $* * *$ \\
\hline R3:South & 0.057 & & -0.114 & $* * *$ & -0.072 & * & -0.122 & $* * *$ & -0.094 & $* *$ & -0.145 & $* *$ & -0.064 & $* *$ & -0.140 & $* * *$ & -0.128 & $* * *$ & -0.089 & ** \\
\hline R4: South-West & -0.017 & & -0.075 & $*$ & -0.162 & $* * *$ & -0.200 & $* * *$ & -0.215 & $* * *$ & 0.007 & & -0.050 & & -0.086 & $* *$ & -0.076 & * & 0.019 & \\
\hline R8: Bucharest & 0.154 & * & -0.090 & $* *$ & -0.050 & & -0.055 & & -0.089 & * & -0.023 & & 0.096 & $* *$ & 0.043 & & -0.025 & & -0.099 & ** \\
\hline Hungarians*Center & -0.225 & & -0.403 & & -0.150 & & 0.242 & & -0.434 & & -0.761 & & -0.287 & & -0.185 & & 0.101 & & -0.428 & \\
\hline Married & -0.046 & & -0.013 & & 0.031 & & -0.030 & & 0.004 & & -0.046 & & -0.127 & $* * *$ & -0.105 & $* * *$ & -0.225 & $* * *$ & -0.071 & * \\
\hline Urban & -0.109 & $* *$ & 0.072 & $* *$ & -0.020 & & -0.056 & & -0.014 & & 0.034 & & 0.032 & & -0.009 & & 0.026 & & 0.082 & $* * *$ \\
\hline \multicolumn{21}{|l|}{ Ethnicity ${ }^{2)}$} \\
\hline Romanian & -0.234 & * & -0.083 & & -0.025 & & -0.003 & & -0.015 & & -0.212 & * & -0.042 & & -0.053 & & -0.154 & * & -0.009 & \\
\hline Hungarian & 0.048 & & 0.330 & & 0.067 & & -0.201 & & 0.404 & & 0.635 & & 0.255 & & 0.060 & & -0.196 & & 0.575 & \\
\hline Group $^{3)}$ & & & & & & & & & & & & & & & & & & & & \\
\hline
\end{tabular}


Table 1 Selection equation estimates, by gender, 1960-2000 (Continued)

\begin{tabular}{|c|c|c|c|c|c|c|c|c|c|c|c|c|c|c|c|c|c|c|c|c|}
\hline Agriculture & & & -0.538 & $* * *$ & -0.563 & $* * *$ & -0.327 & $* * *$ & -0.208 & $* *$ & & & -0.523 & $* * *$ & -0.457 & $* * *$ & -0.352 & $* * *$ & -0.437 & $* * *$ \\
\hline Industry & & & -0.565 & $* * *$ & -0.477 & $* * *$ & -0.428 & $* * *$ & -0.433 & $* * *$ & & & 0.127 & *** & 0.217 & $* * *$ & 0.227 & $* * *$ & 0.116 & *** \\
\hline Private ownership & 0.406 & $* * *$ & 0.046 & & 0.034 & & -0.040 & & -0.135 & $* * *$ & -0.179 & $* *$ & 0.138 & $* * *$ & 0.099 & $* * *$ & 0.065 & $* *$ & 0.107 & *** \\
\hline Children aged $<18$ & -0.072 & $* * *$ & -0.048 & $* * *$ & -0.042 & $* * *$ & -0.041 & $* * *$ & -0.006 & & -0.020 & & 0.010 & & 0.010 & & 0.020 & & -0.022 & * \\
\hline Multi-generation household & -0.086 & & 0.058 & & 0.014 & & -0.097 & $* *$ & 0.062 & & 0.034 & & 0.010 & & 0.065 & * & 0.033 & & 0.109 & *** \\
\hline \multicolumn{21}{|l|}{ Variance-covariances } \\
\hline $\operatorname{Var}\left(U_{1}\right)$ & 0.158 & $* *$ & 0.230 & $* * *$ & 0.231 & $* * *$ & 0.276 & $* * *$ & 0.274 & $* * *$ & 0.143 & $* * *$ & 0.233 & $* * *$ & 0.266 & $* * *$ & 0.259 & $* * *$ & 0.363 & $* * *$ \\
\hline $\operatorname{Var}\left(U_{2}\right)$ & 0.362 & $* * *$ & 0.196 & $* * *$ & 0.196 & $* * *$ & 0.180 & $* * *$ & 0.201 & $* * *$ & 0.246 & $* * *$ & 0.203 & $* * *$ & 0.203 & $* * *$ & 0.186 & *** & 0.210 & $* * *$ \\
\hline $\operatorname{Var}\left(U_{3}\right)$ & 0.275 & $* * *$ & 0.236 & $* * *$ & 0.209 & $* * *$ & 0.159 & $* * *$ & 0.188 & $* * *$ & 0.148 & $* * *$ & 0.177 & $* * *$ & 0.129 & $* * *$ & 0.156 & $* *$ & 0.464 & $* * *$ \\
\hline $\operatorname{Cov}\left(U_{1}, \varepsilon\right)$ & -0.241 & & -0.284 & $* * *$ & -0.332 & $* * *$ & -0.380 & $* * *$ & -0.381 & $* * *$ & 0.010 & & -0.329 & $* * *$ & -0.402 & $* * *$ & -0.391 & $* * *$ & 0.516 & $* * *$ \\
\hline $\operatorname{Cov}\left(U_{2}, \varepsilon\right)$ & -0.300 & $* * *$ & -0.245 & $* * *$ & -0.279 & $* * *$ & -0.292 & $* * *$ & -0.319 & $* * *$ & 0.142 & $* * *$ & -0.264 & $* * *$ & -0.293 & $* * *$ & -0.271 & $* * *$ & 0.292 & $* * *$ \\
\hline $\operatorname{Cov}\left(U_{3}, \varepsilon\right)$ & -0.461 & $* * *$ & -0.374 & $* * *$ & -0.271 & $* * *$ & -0.162 & $* *$ & -0.243 & $* * *$ & -0.103 & & -0.255 & ** & -0.085 & & 0.139 & & 0.619 & $* * *$ \\
\hline Likelihood & -6266.7 & & -12476.5 & & -11197.5 & & -9426.8 & & -8267.2 & & -6923.4 & & -17877.1 & & -15364.5 & & -13023.9 & & -10944 & \\
\hline
\end{tabular}

Notes: The estimate is significant at the $10 \%$ level $(*)$, at the $5 \%$ level $(* *)$, and at the $1 \%$ level $\left({ }^{* * *}\right)$. These notes hold for all tables of estimates. ${ }^{(1)}$ The comparison group is compulsory; ${ }^{(2)}$ the comparison group is all other ethnicities; ${ }^{(3)}$ the comparison group is services. Dummies for 5 -year plan periods and three dummies for ownership were also included. 
For women, the estimated correlations are negative for all analyzed samples, suggesting the existence of hierarchical sorting. This finding indicates that women performed similarly in all occupational groups during both the communist regimes and the transition years. However, this was not the case for men.

For men, the covariances have different signs for the communist period, which suggests that men's sorting into occupational groups during this regime was consistent with the theory of comparative advantage (Roy 1951), which suggests that those who perform relatively well in one occupational group will perform relatively more poorly in another occupational group. More exactly, a given man selected the occupation that paid him better than the average worker with the same characteristics and under the same working circumstances. Except for 2000, when all were positive, the correlations were negative for all the other transition years, suggesting hierarchical sorting. This sorting structure implies that there was a positive selection into one group and a negative selection into the other group.

In addition to the notable differences in the sorting behavior of men and women across occupational groups revealed by the covariance parameters, the other parameters also reveal differences between men and women during the two eras. We use age as a proxy for the different regulation and structural changes that people born in different cohorts were facing. We use the continuous variable instead of age intervals to avoid multicollinearity with the educational dummies. The estimated parameters are significant for women during the communist period and in 1994 and 2000 but only for men in 1994, and they indicate that the probability of choosing a female-dominated occupation increased with age during these years.

The highest education level attained is strongly correlated with both the men's and women's occupational choice. However, women's parameters are much higher than men's and are always positive, a finding that suggests that women are more oriented towards female-dominated occupations when they have schooling beyond compulsory education. During all analyzed years of the transition, the higher education parameter is statistically significant only for men, which indicates the collapse of the socialist support for women in male-dominated occupations but also the freedom of the market economy, which restructures jobs, occupations and the way men and women choose their occupations.

The geographical region where people live was also correlated with the occupational choice of both men and women; both men and women living in some regions with a large majority of ethnic Romanians ( $\mathrm{R} 1$ and $\mathrm{R} 2$, which are also relatively poorer regions) had a lower probability of choosing to work in a female-dominated occupation than those living in a region with an ethnic overrepresentation (R5-R7). However, being an ethnic Hungarian living in a region with a relatively high concentration of ethnic Hungarians did not have a statistically significant effect on occupational choice. This finding might suggest that the policy of territorial development during the communist years made the regions with an ethnic overrepresentation more heterogeneous than the others. The same explanation might be used for the relationship between people living in urban areas and occupational choice, which was statistically significant for men in 2000 and for women during the communist regime and in 1994. Women who lived in an urban area had a lower probability of choosing a female-dominated occupation during the communist regime but a higher probability in 1994. Men who lived in an urban area had a higher probability of working in a female-dominated occupation in 2000 . 
These findings might be explained by the structural changes that made it more attractive for men to work in occupations within the banking and insurance industries or as real estate agents and accountants. The results for the communist period might be explained by the concentration of big industries in the urban area, whereas the results for the transition might indicate that the changes in that era (such as the restructuring or the total collapse of the big industrial firms and the entire agricultural system as well as the increased private initiatives oriented primarily towards commerce and services) reallocated male labor towards female-dominated occupations.

The effect of the number of children younger than 18 in the household on occupational choice was significant (and negative) for women in all years except in 2000 but only in 2000 for men. The significant parameters indicate that those with more children were more likely to work in male-dominated or gender-integrated occupations, which suggests that family structure might influence occupational choice.

\subsection{Decomposing the gender wage gap}

\subsubsection{The overall gender wage gap}

Table 2 presents the evolution of the observed gender wage gap and its components for the entire sample (i.e., all occupational groups together). The first component of the decomposition is related to endowments and comes from differences in observables such as age, education, and other socioeconomic factors important for wage setting. The second component (referred to as the occupational effect) is related to differences between men and women in both the structure of occupational attainment and their qualifications for their chosen occupation. The third component (referred to as the selectivity effect) is related to self-selection into occupations, which is driven by the unobservables. Because occupational choice is made on the basis of an individual's preferences, skills, or abilities related to different work tasks, this self-selected choice could potentially affect the wages positively under the assumption that strong preferences and productivity have a positive association. If the mean selection effect for men is stronger than for women, the total effect will be positive (as was the case in all analyzed years except 2000). However, if the sorting into different occupations is random, the corresponding effect will be zero. The fourth component (referred to as the unexplained effect) comes from differences in the return to observables between men and women. Except for 2000, when the magnitude of this component was very low, all other transition years had values higher than before 1989.

The observed overall gender wage gap, measured as the difference between the mean log wages of male and female workers, stood at 0.28 during the communist era. In other words, the average female worker earned approximately $72 \%$ of the mean male wage. Whereas the observed gender wage gap has remained almost constant during the transition period, the relative importance of the individual components of the decomposition varies across years, with much higher variations in both female-dominated and male-dominated occupations. These results support our earlier hypotheses and explanations about the effects of the structural changes in the economy during the transition period on both labor reallocation and wage setting across occupations. The communist direction of gender equality spotlighted examples of "women heroes" working in typically masculine areas, i.e., in mines underground, in industrial, chemical, and 
Table 2 Overall gender wage gap decomposition, all occupations 1960-2000

\begin{tabular}{lrrrrr}
\hline & $\mathbf{1 9 6 0 - 1 9 8 9}$ & $\mathbf{1 9 9 4}$ & $\mathbf{1 9 9 6}$ & $\mathbf{1 9 9 8}$ & $\mathbf{2 0 0 0}$ \\
\hline Observed & 0.280 & 0.205 & 0.221 & 0.189 & 0.214 \\
Endowments & 0.048 & -0.016 & -0.009 & -0.016 & -0.015 \\
Occupational & 0.001 & -0.125 & -0.091 & -0.041 & 0.252 \\
Selectivity & 0.050 & 0.040 & 0.035 & 0.022 & -0.061 \\
Unexplained & 0.172 & 0.302 & 0.286 & 0.223 & 0.036 \\
\hline
\end{tabular}

Notes: Observed represents total wage gap in mean wages. The total wage gap is decomposed into four parts: Endowments that represents the contribution to the wage gap from differences in observables; Occupational represents the contribution from unequal distribution of men and women over occupational groups; Selectivity represents the contribution from differences in unobservables and finally, Unexplanied that represents the contribution from differences in return to observables.

metallurgical operations, and in areas such as surgery and experimental sciences. Our results show that on average, women were better off during the transition. However, this holds only for the formal market. Given that the informal market was growing substantially during the analyzed years of transition, it might be that, on average, women are much more discriminated now.

Our results suggest that some of the traditional motivations for the existence of the gender wage gap, as in Becker's (1957) model, are not supported by the institutional settings of a planned economy (education, experience, and the discriminatory tastes of employers, co-workers, or customers). Although women were expected to deliver increasingly more children (due to the 1966 abortion ban and almost no information about or supply of birth control), and the Romanian society is characterized by strong cultural traditions that hold women responsible for the proper functioning of the household, women (from our samples) invested in education and worked in almost the same way that men did. Women tended to work the same amount of work hours as men (in the same occupation), but due to the cultural norms, women continued to spend longer hours doing housework, which might have decreased their labor productivity in the workplace. However, they received fixed monthly wages instead of decreased wages, as Becker (1985) suggested (for a market economy). This was the case even during the first years of transition.

\subsubsection{The gender wage gap by occupational group}

Table 3 presents the decomposition within each occupational group, which, for obvious reasons, does not include any occupational effect other then the effect that comes from self-selection. The wage differential between males and females was different across groups, with the highest observed differences in the gender-integrated occupations during all analyzed years. In this group, the observed gender wage gap was highest during the communist regime, whereas the observed wage gaps for the other two groups were almost zero: $2.7 \%$ in male-dominated occupations and $0.1 \%$ in female-dominated occupations. These numbers are in accordance with the official policy of gender equality during the communist regime, when wages were set according to industry-specific wage grids and varied only with the difficulty of the job and with workers' education and experience, not with gender. Compared to other groups, the female-dominated occupations were characterized by a lower difficulty of job tasks and a lower risk for accidents, which implies a lower "bonus." These occupations were also more homogenous 
Table 3 Gender wage gap decomposition by sector, 1960-2000

\begin{tabular}{lrrrrr}
\hline & $\mathbf{1 9 6 0 - 1 9 8 9}$ & \multicolumn{1}{c}{$\mathbf{1 9 9 4}$} & $\mathbf{1 9 9 6}$ & $\mathbf{1 9 9 8}$ & $\mathbf{2 0 0 0}$ \\
\hline Male-dominated (MD) occupations & & & & & \\
Observed & 0.027 & 0.164 & 0.099 & 0.081 & 0.146 \\
Endowments & -0.096 & -0.026 & -0.049 & -0.043 & -0.116 \\
Selectivity & -0.481 & -0.073 & -0.077 & -0.204 & -1.394 \\
Unexplained & 0.585 & 0.257 & 0.226 & 0.333 & 1.649 \\
Gender-integrated (GI) occupations & & & & & \\
Observed & 0.316 & 0.217 & 0.245 & 0.202 & 0.219 \\
Endowments & 0.070 & -0.016 & -0.006 & -0.013 & -0.011 \\
Selectivity & 0.040 & -0.104 & -0.103 & -0.102 & 0.054 \\
Unexplained & 0.198 & 0.332 & 0.352 & 0.315 & 0.177 \\
Female-dominated (FD) occupations & & & & & \\
Observed & 0.009 & 0.110 & 0.115 & 0.081 & 0.145 \\
Endowments & -0.051 & -0.009 & 0.002 & -0.025 & 0.015 \\
Selectivity & 0.516 & -0.053 & 0.186 & 0.551 & 1.723 \\
Unexplained & -0.458 & 0.168 & -0.068 & -0.446 & -1.590 \\
\hline
\end{tabular}

Notes: Observed represents total wage gap in mean wages. The total wage gap is decomposed into three parts: Endowments that represents the contribution to the wage gap from differences in observables; Selectivity represents the contribution from differences in unobservables and, Unexplanied that represents the contribution from differences in return to observables.

with respect to requirements for education (for example, nurses and teachers for the first four grades had graduated from specialized high schools), which also implies relatively lower wages. On the contrary, almost all male-dominated occupations were characterized by some degree of difficulty and/or risk, which increased the average wages. Moreover, it may have happened that women who worked in that occupational group chose occupations with a lower degree of difficulty, and therefore, their average wages were lower. The gender-integrated occupations may have included a diversity of occupations that could be rewarded differently because of the different degrees of difficulty and various levels of education. The selection into these occupations may explain the gender wage gap. However, the endowments, or the part of the gender wage gap explained by the observables, offer another picture of the gender gap. The explained part is negative and much higher in magnitude than the observed gender wage gap in both male-dominated and female-dominated occupations. This finding indicates that women's returns to endowments were higher than those of their male peers. This was not the case for the gender-integrated occupations, where the observables explain approximately $26 \%$ of the gender wage gap.

During the analyzed transition years, the observed gender wage gap increased in male-dominated and female-dominated occupations and decreased in genderintegrated occupations, although the magnitude was still the highest in this sector. The observed gaps were the same in the male- and female-dominated occupations in 1998 (approximately 8\%) and 2000 (approximately 14.5\%). Except for female-dominated occupations in 1996 and 2000, the component of the gap explained by the observables was negative for all other analyzed years and sectors. In the gender-integrated and female-dominated occupations, the magnitude of this component was (approximately 
0.01) smaller than during the communist period. In the male-dominated occupations, the magnitude was relatively higher than in the other sectors $(0.04)$ and even higher in $2000(0.116)$ than during the communist period. It is notable that when controlling for selection into an occupation, the unexplained component of the gender wage gap varied greatly across years in the male-dominated occupations, and it was almost the mirror image of the evolution of this component for the female-dominated occupations. This finding suggests once more that the transition changes had a direct effect on the labor reallocation of men and women but also on the pay in various female-dominated occupations (with much higher wages in banking and accounting) and male-dominated occupations. This finding suggests that the market economy played its role by bringing the wages to different levels, and policies such as affirmative action had only a limited effect on the level of the unexplained wage gap. Nevertheless, the unexplained component of the wage gap was negative for femaledominated occupations during communist era and the last transition years (1996, 1998, and 2000) and positive and relatively high in all other sectors during all analyzed years. This finding might suggest that women working in female-dominated occupations were rewarded better than their male peers in 1996, 1998 and 2000, everything else being the same.

\subsection{Decomposing the occupational wage gap}

Table 4 presents the observed occupational wage gap (MD-FD; MD-GI; and FD-GI) and its components for men and women, respectively. The first component (i.e., endowments) represents the wage difference due to observed and explained factors. The second component (i.e., selectivity) contains wage effects from unobserved individual characteristics that influence the wage of the individual. The third component (i.e., unexplained) should be seen as an occupational effect, expressing the fact that some factors are rewarded differently in different occupations. All observed occupational wage gaps were positive for men, whereas for women, the observed MD-FD differences were negative but almost zero during the transition period and in 1994. Except for these two periods, the occupational wage gaps were relatively lower for men than for women. Most years, the men's values were lower than 0.1 (or 10\%), whereas the women's values were more often 0.1-0.2, indicating that men's average wages did not differ significantly over time. Moreover, the part of the men's occupational wage gap explained by endowments was positive only for the FD-GI gap during the communist period and in 2000, and for the MD-FD gap in 1998. All other twelve values were negative, which might suggest that the wages of "the average observables" for men were lower in the first sector (MD or FD) than in the second (FD or GI); here, first and second refer to the order of comparison. Nevertheless, the women's MD-FD gap explained by their endowments was positive and much higher than the observed gap during all years of transition. This finding suggests that "the average observables" for women was much higher in MD-occupations than in FD-occupations.

The unexplained portion of the wage gap is often interpreted as a result of discrimination. Under this view, once differences among women in the relevant determinants of wages are taken into account, any remaining difference in pay must be due to 
Table 4 Occupational wage gap (owg) decomposition by gender

\begin{tabular}{|c|c|c|c|c|c|c|}
\hline & & $1960-89$ & 1994 & 1996 & 1998 & 2000 \\
\hline \multicolumn{7}{|l|}{ Women } \\
\hline \multirow[t]{4}{*}{ MD-FD owg } & Observed & -0.003 & -0.013 & 0.055 & 0.052 & 0.034 \\
\hline & Endowments & 0.113 & 0.077 & 0.112 & 0.116 & 0.168 \\
\hline & Selectivity & 1.186 & 0.985 & 0.961 & 0.941 & 1.051 \\
\hline & Unexplained & -1.302 & -1.075 & -1.018 & -1.005 & -1.185 \\
\hline \multirow[t]{4}{*}{ MD-Gl owg } & Observed & 0.415 & 0.120 & 0.203 & 0.200 & 0.199 \\
\hline & Endowments & 0.154 & -0.015 & 0.006 & -0.002 & 0.036 \\
\hline & Selectivity & 0.460 & 0.451 & 0.575 & 0.692 & 0.687 \\
\hline & Unexplained & -0.199 & -0.316 & -0.378 & -0.490 & -0.523 \\
\hline \multirow[t]{4}{*}{ FD-Gl owg } & Observed & 0.417 & 0.133 & 0.148 & 0.148 & 0.165 \\
\hline & Endowments & -0.004 & -0.110 & -0.112 & -0.057 & -0.029 \\
\hline & Selectivity & -0.726 & -0.534 & -0.385 & -0.248 & -0.365 \\
\hline & Unexplained & 1.147 & 0.778 & 0.646 & 0.453 & 0.560 \\
\hline \multicolumn{7}{|l|}{ Men } \\
\hline \multirow[t]{4}{*}{ MD-FD owg } & Observed & 0.015 & 0.040 & 0.039 & 0.053 & 0.034 \\
\hline & Endowments & -0.064 & -0.026 & -0.045 & 0.006 & -0.085 \\
\hline & Selectivity & 0.207 & 0.967 & 0.700 & 0.181 & -0.669 \\
\hline & Unexplained & -0.128 & -0.901 & -0.617 & -0.134 & 0.789 \\
\hline \multirow[t]{4}{*}{ MD-Gl owg } & Observed & 0.126 & 0.067 & 0.057 & 0.079 & 0.126 \\
\hline & Endowments & -0.018 & -0.040 & -0.036 & -0.025 & -0.045 \\
\hline & Selectivity & -0.050 & 0.483 & 0.598 & 0.584 & 0.007 \\
\hline & Unexplained & 0.194 & -0.377 & -0.505 & -0.481 & 0.163 \\
\hline \multirow[t]{4}{*}{ FD-Gl owg } & Observed & 0.110 & 0.026 & 0.019 & 0.026 & 0.091 \\
\hline & Endowments & 0.094 & -0.050 & -0.045 & -0.089 & -0.005 \\
\hline & Selectivity & -0.257 & -0.484 & -0.102 & 0.404 & 0.676 \\
\hline & Unexplained & 0.273 & 0.560 & 0.166 & -0.288 & -0.580 \\
\hline
\end{tabular}

Notes: Observed represents total wage gap in mean wages. The total wage gap is decomposed into three parts: Endowments that represents the contribution to the wage gap from differences in observables; Selectivity represents the contribution from differences in unobservables and, Unexplanied that represents the contribution from differences in return to observables.

discrimination. This cannot be gender discrimination but something else that we cannot observe. However, except for women's MD-FD samples, for all other samples, the unexplained part of the gap was positive and, with a few exceptions, higher in magnitude than the observed gaps. During the communist era, this might be a direct reflection of the institutional settings of the labor market and the social security system, which gave privileges (such as access to, e.g., day care, health care, and subsidized lunches) only to workers from given companies, and the variation in the unexplained part of the occupational wage gap during the transition period could be due to a relative improvement in unmeasured labor market skills. Nevertheless, the choice of occupation is related to the institutional and democratic settings, and therefore, the results are a reflection of the multitude of changes that occurred during the transition years. An individual with preferences associated with a typical female occupation will be more likely to enter an FD occupation than someone with preferences associated with a typical male occupation. 


\section{Summary and conclusions}

Since the communist regime's fall in December 1989, Romania has experienced profound political, democratic, and economic transformations. The labor market is one arena that has experienced the most market economy shocks, including the official birth of unemployment and its social implications, the restructuring process of almost all big industrial companies and the entire agricultural sector, the expansion of the private sector, the composition of employment, and a decentralized system of wage setting. All of these changes open up the question of whether the "planned equality" of the communist regime transformed into a "market inequality" during the transition years. Using data from cross-sectional household surveys conducted during the transition years in Romania, which include unique retrospective information about starting wages and occupations since the 1960s, our results show that the unexplained part of the gender wage gap was lower during the communist regime and higher during the transition years.

Contrary to previous results based on data of Central and Eastern Europe that reveal that the gender wage gap generally decreased in the transition process, our results show that the gender wage differentials remained stable during the transition years. This result may suggest that the structural changes that occurred in 19942000 played a limited role in determining the gender wage gap for those who worked. However, the more predominant reallocation of male labor from the public to the private sector (due primarily to the mass privatization of the state enterprises) was expected to increase wage inequality and to result in a wider gender wage gap. Nevertheless, our result is in line with the literature that reported that the gender wage gap has been relatively stable through the 1990s in several transition economies (Newell and Reilly 2000).

We found low values of the gender wage gap in female- and male-dominated occupations during the communist years, which supports the hypothesis that if solidarity wage bargaining were effective in promoting equal pay for equal job types, then controlling for job characteristics should generate an adjusted wage gap of zero. In other words, this suggests some effects of wage bargaining in securing the equal treatment of men and women in the Romanian labor market during the communist regime.

The decomposition of the gender wage gap shows that the endowments (or the observables) had a negative contribution to the overall difference. Moreover, during the last analyzed transition years, the unexplained and the selection components of the wage gap developed in opposite directions for male-dominated and femaledominated occupations. The unexplained component was negative only for the female-dominated occupations, which might suggest that women working in the female-dominated occupations were getting a "gender bonus". Nevertheless, the "unadjusted" gender gap might be explained (largely) by nondiscriminatory factors, such as family responsibilities and particularly the different involvement of men and women in housework. However, given that the economy and society in general and the labor market in particular experienced a multitude of complex changes during the analyzed period, it is possible that much of the wage gap is due to institutional norms, employer practices, and labor market policies. These three elements changed continuously and reflect the structural conditions of the labor market and the 
societal restrictions, which may create not only different labor market opportunities for different groups of people but also relative values of different occupations in society.

The fact that women were more risk adverse than men in the new free market economy created an advantage for men, who become over-represented in higher wage occupations, such as managers and politicians. Therefore, it is not surprising that occupational differences explain a significant portion of the overall gender wage gap during the transition years. However, the macro statistics show that in the first years of the transition, men were more affected than women by the restructuring and closing of big factories, and therefore, it could be that men who did not find a job contributed to reducing the weight of the men situated at the low end of the distribution of the offered wages. Although the labor participation of men and women was high during the communist era (exceeding 90\%) and even in the first years of transition (approximately 75\%), the selection biases-due to our observation of only the wages of persons who worked in the formal sector-might be a relatively high source of errors in the assessment of wage differentials between groups and in the evaluation of the components of these differentials.

Nevertheless, our results indicate that the wage differences were, in general, much higher among workers of the same gender working in different occupations than between men and women working in the same occupational group, and women experienced a larger variation of occupational wage differentials than men during both regimes. These results seem to be in line with earlier literature that supports the belief that gender differences in preferences play some role in gender differences in occupations (Gunderson 1989). The rise in women's acquisition of career-oriented formal education may reflect changes not only in women's preferences and their response to greater market opportunities but also in the admission practices of educational institutions and the responses of other institutions that supported the promotion of women in a male-dominated world. In Romania, these factors were strong during the communist period but weak, almost absent (in a broad perspective), during the first years of transition; this might have contributed to the fact that the gender wage gap was low during the communist regime and higher during the transition years. This implies that if policy makers are concerned with these issues, they should help women more to gain a career-oriented formal education. Additionally, women should be given assistance in becoming motivated to participate in the labor market in general but also to choose occupations that match their education.

During the transition years analyzed in this paper, Romania had no sustained debate about "making work pay;" instead, in the preparation for a European Union (EU) membership, the focus has been on preparing the legal and institutional processes and developing economic and social policy in line with EU guidelines and requirements. However, the EU has an explicit commitment to raising the employment rate for women and to advancing gender mainstreaming and gender equality in both employment and social inclusion policies. Moreover, even the measure of the gender pay gap is part of the EU's list of "structural indicators" (designed, after the Lisbon Special European Council in March 2000, to follow up on progress regarding employment and other issues).

\section{Endnotes}

${ }^{1}$ e.g., Katz (1994, 1997), Newell and Reilly (1996) and Ogloblin (1999) using data after the first years of transition in Russia, Jurajda (2003) using employer-employee data sets 
Table 5 The public opinion about Who should be employed in the following domains

\begin{tabular}{lrrr}
\hline Domain & Men & Women & Gender is not important \\
\hline Agriculture & 0.22 & 0.02 & 0.76 \\
Mining and metallurgy & 0.87 & 0 & 0.13 \\
Textile industry & 0.03 & 0.74 & 0.23 \\
Construction & 0.83 & 0 & 0.17 \\
Transportation & 0.64 & 0 & 0.37 \\
Education & 0.03 & 0.25 & 0.72 \\
Health & 0.03 & 0.21 & 0.76 \\
Public administration & 0.17 & 0.07 & 0.76 \\
Non-Governmental organizations & 0.12 & 0.10 & 0.77 \\
Media & 0.06 & 0.06 & 0.88 \\
Food Industry/Commerce & 0.03 & 0.25 & 0.72 \\
Banking System & 0.16 & 0.09 & 0.75 \\
Justice & 0.28 & 0.04 & 0.69 \\
Government & 0.42 & 0.02 & 0.56 \\
\hline
\end{tabular}

from the Czech Republic and Slovakia in 1998, and Jurajda and Harmgart (2007) for East (and West) Germany in 1995.

${ }^{2}$ The only two studies of the gender wage gap in Romania during the first years of transition (e.g., Paternostro and David 1999; Skoufias 2003) reported similar results as studies that used data from other socialist countries of Central and Eastern Europe and the former Soviet Union: the gender wage gap generally decreases in the transition process (Brainerd 1998, 2000).

${ }^{3}$ The Gender Barometer of the Open Society Foundation covers a representative sample of 1,839 persons aged 18 and over, and it is the first documented attempt to examine the Romanian society in terms of the roles of men and women, their relationships, and their everyday life (see Table 5).

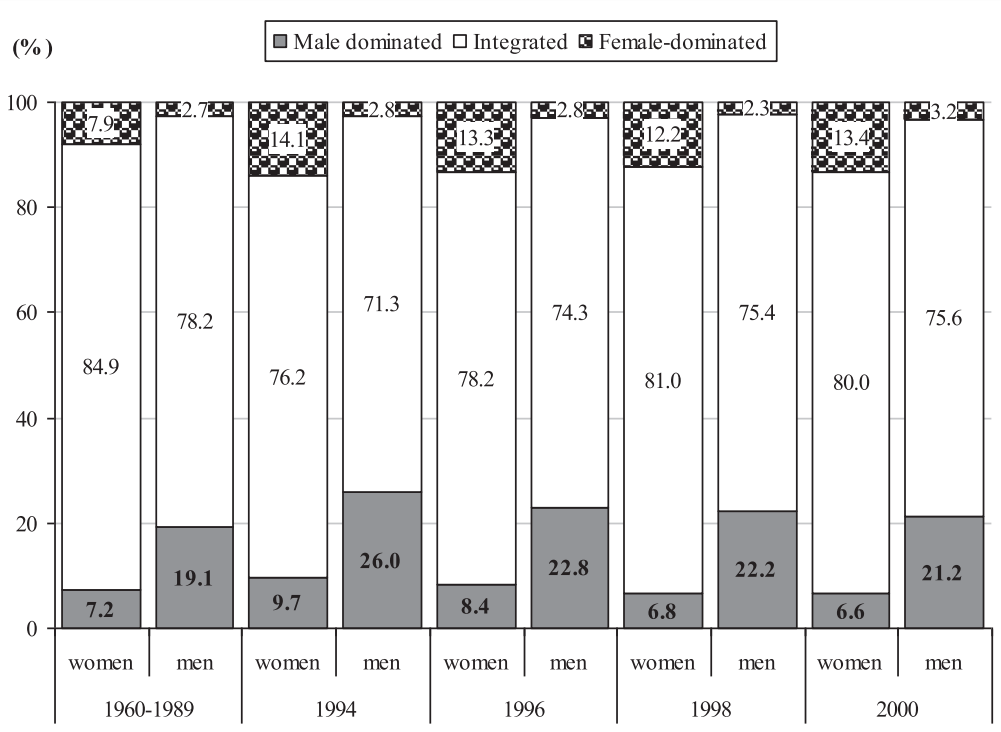

Figure 3 The distribution of the occupational groups, 1960-2000, selected years. 
${ }^{4}$ e.g., Hansen and Wahlberg (2008), Macpherson and Hirsch (1995), Sorensen (1989, 1990) and England et al. (1988).

${ }^{5}$ The model, defined by equations (1)-(4) contains 4 stochastic components. In principle, one can allow for any potential correlation among the stochastic components. However, for a given individual, we only observe the actual wage and the indicated occupational choice in pairs, and not simultaneously with wages in other occupations. Therefore, the observability is partial, and we have to make inference on

Table 6 Descriptive statistics, male-dominated occupations

\begin{tabular}{|c|c|c|c|c|c|c|c|c|c|c|}
\hline & \multicolumn{2}{|c|}{$1960-89$} & \multicolumn{2}{|l|}{1994} & \multicolumn{2}{|l|}{1996} & \multicolumn{2}{|l|}{1998} & \multicolumn{2}{|l|}{2000} \\
\hline & Men & Women & Men & Women & Men & Women & Men & Women & Men & Women \\
\hline Wage $^{\#}$ & 1.472 & 1463.18 & 151.78 & 128.89 & 328.86 & 297.55 & 992.60 & 907.56 & 2348.77 & 2073.2 \\
\hline Age & 27.69 & 25.0 & 39.27 & 37.60 & 39.11 & 37.97 & 39.68 & 38.80 & 39.60 & 39.06 \\
\hline \multicolumn{11}{|l|}{ Education } \\
\hline Lower education & 0.76 & 0.66 & 0.67 & 0.56 & 0.66 & 0.53 & 0.65 & 0.49 & 0.61 & 0.48 \\
\hline Medium education & 0.17 & 0.29 & 0.26 & 0.38 & 0.26 & 0.39 & 0.26 & 0.42 & 0.30 & 0.43 \\
\hline Higher education & 0.06 & 0.04 & 0.07 & 0.06 & 0.08 & 0.08 & 0.08 & 0.08 & 0.09 & 0.09 \\
\hline \multicolumn{11}{|l|}{ Region } \\
\hline R1: North-East & 0.20 & 0.18 & 0.14 & 0.14 & 0.14 & 0.13 & 0.13 & 0.13 & 0.13 & 0.16 \\
\hline R2: South-East & 0.17 & 0.15 & 0.15 & 0.13 & 0.16 & 0.14 & 0.16 & 0.16 & 0.15 & 0.15 \\
\hline R3: South & 0.18 & 0.16 & 0.18 & 0.20 & 0.17 & 0.16 & 0.18 & 0.20 & 0.17 & 0.15 \\
\hline R4: South-West & 0.09 & 0.09 & 0.12 & 0.10 & 0.11 & 0.10 & 0.11 & 0.11 & 0.11 & 0.10 \\
\hline R5: West & 0.09 & 0.12 & 0.11 & 0.08 & 0.11 & 0.08 & 0.10 & 0.07 & 0.10 & 0.09 \\
\hline R6: North-West & 0.12 & 0.13 & 0.12 & 0.12 & 0.13 & 0.15 & 0.11 & 0.10 & 0.14 & 0.12 \\
\hline R7: Center & 0.09 & 0.10 & 0.11 & 0.11 & 0.10 & 0.11 & 0.12 & 0.12 & 0.11 & 0.10 \\
\hline R8: Bucharest & 0.06 & 0.08 & 0.08 & 0.12 & 0.08 & 0.12 & 0.09 & 0.12 & 0.10 & 0.13 \\
\hline Married & 0.84 & 0.78 & 0.83 & 0.80 & 0.82 & 0.79 & 0.84 & 0.80 & 0.82 & 0.79 \\
\hline Urban & 0.51 & 0.72 & 0.55 & 0.74 & 0.54 & 0.74 & 0.57 & 0.78 & 0.63 & 0.82 \\
\hline \multicolumn{11}{|l|}{ Ethnicity } \\
\hline Romanian & 0.92 & 0.93 & 0.94 & 0.95 & 0.94 & 0.94 & 0.94 & 0.95 & 0.94 & 0.94 \\
\hline Hungarian & 0.06 & 0.06 & 0.05 & 0.04 & 0.05 & 0.05 & 0.05 & 0.04 & 0.05 & 0.05 \\
\hline Other & 0.02 & 0.01 & 0.01 & 0.01 & 0.01 & 0.01 & 0.01 & 0.00 & 0.01 & 0.01 \\
\hline \multicolumn{11}{|l|}{ Sector } \\
\hline Agriculture & & & 0.21 & 0.12 & 0.19 & 0.11 & 0.15 & 0.10 & 0.12 & 0.06 \\
\hline Industry & & & 0.36 & 0.74 & 0.32 & 0.67 & 0.32 & 0.68 & 0.32 & 0.69 \\
\hline Services & & & 0.42 & 0.14 & 0.49 & 0.22 & 0.53 & 0.22 & 0.55 & 0.25 \\
\hline \multicolumn{11}{|l|}{ Ownership } \\
\hline State & 0.83 & 0.88 & 0.89 & 0.92 & 0.80 & 0.80 & 0.67 & 0.65 & 0.48 & 0.36 \\
\hline Private & 0.09 & 0.05 & 0.08 & 0.05 & 0.14 & 0.13 & 0.23 & 0.20 & 0.37 & 0.47 \\
\hline Other & 0.06 & 0.04 & 0.01 & 0.02 & 0.00 & 0.02 & 0.00 & 0.01 & 0.00 & 0.01 \\
\hline $\begin{array}{l}\text { Household } \\
\text { members }\end{array}$ & 3.56 & 3.57 & 3.95 & 3.74 & 3.84 & 3.68 & 3.76 & 3.62 & 3.64 & 3.42 \\
\hline $\begin{array}{l}\text { Multi-generation } \\
\text { household }\end{array}$ & 0.12 & 0.12 & 0.21 & 0.14 & 0.21 & 0.15 & 0.21 & 0.15 & 0.20 & 0.13 \\
\hline Children $<18$ & 0.88 & 1.04 & 1.20 & 1.14 & 1.10 & 1.07 & 0.99 & 0.99 & 0.95 & 0.88 \\
\hline$n$ & 1190 & 351 & 3887 & 1025 & 3137 & 860 & 2680 & 643 & 2025 & 521 \\
\hline
\end{tabular}

Note: "monthly wage in thousands of Romanian lei, and it is the starting wage for 1951-1989. This holds for all tables. 
the population based on marginal distributions that correspond to the observed data. In particular, $\operatorname{cov}\left(U_{1}, \varepsilon\right), \operatorname{cov}\left(U_{2}, \varepsilon\right)$ and $\operatorname{cov}\left(U_{3}, \varepsilon\right)$ are identified by the data and are therefore allowed to be non-zero, while the covariances among the residuals from the output equations, $\operatorname{cov}\left(U_{1}, U_{2}\right), \operatorname{cov}\left(U_{1}, U_{3}\right)$ and $\operatorname{cov}\left(U_{2}, U_{3}\right)$, are left unspecified. The variances of the output equations, $\operatorname{var}\left(U_{1}\right), \operatorname{var}\left(U_{2}\right)$ and $\operatorname{var}\left(U_{3}\right)$, are identified, and we choose to normalize the variance of the residual of the selection equation to 1 .

Table 7 Descriptive statistics, gender-integrated occupations

\begin{tabular}{|c|c|c|c|c|c|c|c|c|c|c|}
\hline & \multicolumn{2}{|l|}{$1960-89$} & \multicolumn{2}{|l|}{1994} & \multicolumn{2}{|l|}{1996} & \multicolumn{2}{|l|}{1998} & \multicolumn{2}{|l|}{2000} \\
\hline & Men & Women & Men & Women & Men & Women & Men & Women & Men & Women \\
\hline Wage $^{\#}$ & 1371.11 & 1166.76 & 142.55 & 114.49 & 308.72 & 243.06 & 911.77 & 742.17 & 2062.32 & 1651.0 \\
\hline Age & 28.20 & 26.90 & 38.89 & 38.07 & 38.83 & 38.00 & 39.37 & 38.70 & 39.62 & 38.62 \\
\hline \multicolumn{11}{|l|}{ Education } \\
\hline Lower education & 0.77 & 0.72 & 0.59 & 0.50 & 0.64 & 0.52 & 0.62 & 0.49 & 0.58 & 0.47 \\
\hline $\begin{array}{l}\text { Medium } \\
\text { education }\end{array}$ & 0.17 & 0.23 & 0.28 & 0.35 & 0.25 & 0.35 & 0.25 & 0.36 & 0.28 & 0.37 \\
\hline Higher education & 0.06 & 0.05 & 0.13 & 0.15 & 0.11 & 0.13 & 0.13 & 0.15 & 0.15 & 0.16 \\
\hline \multicolumn{11}{|l|}{ Region } \\
\hline R1: North-East & 0.22 & 0.22 & 0.13 & 0.13 & 0.13 & 0.14 & 0.13 & 0.14 & 0.13 & 0.14 \\
\hline R2: South-East & 0.11 & 0.11 & 0.12 & 0.11 & 0.11 & 0.11 & 0.12 & 0.12 & 0.11 & 0.11 \\
\hline R3: South & 0.15 & 0.15 & 0.15 & 0.13 & 0.16 & 0.14 & 0.16 & 0.13 & 0.15 & 0.13 \\
\hline R4: South-West & 0.10 & 0.11 & 0.10 & 0.10 & 0.11 & 0.10 & 0.11 & 0.10 & 0.12 & 0.11 \\
\hline R5: West & 0.09 & 0.10 & 0.09 & 0.09 & 0.09 & 0.09 & 0.09 & 0.10 & 0.09 & 0.10 \\
\hline R6: North-West & 0.13 & 0.11 & 0.14 & 0.14 & 0.14 & 0.14 & 0.15 & 0.15 & 0.15 & 0.16 \\
\hline R7: Center & 0.14 & 0.13 & 0.14 & 0.14 & 0.15 & 0.15 & 0.14 & 0.15 & 0.13 & 0.14 \\
\hline R8: Bucharest & 0.07 & 0.07 & 0.13 & 0.15 & 0.11 & 0.12 & 0.10 & 0.12 & 0.11 & 0.12 \\
\hline Married & 0.82 & 0.76 & 0.80 & 0.76 & 0.79 & 0.74 & 0.78 & 0.74 & 0.77 & 0.72 \\
\hline Urban & 0.52 & 0.57 & 0.65 & 0.79 & 0.62 & 0.74 & 0.66 & 0.77 & 0.68 & 0.77 \\
\hline \multicolumn{11}{|l|}{ Ethnicity } \\
\hline Romanian & 0.87 & 0.89 & 0.91 & 0.92 & 0.91 & 0.91 & 0.91 & 0.91 & 0.91 & 0.91 \\
\hline Hungarian & 0.10 & 0.09 & 0.07 & 0.07 & 0.07 & 0.08 & 0.07 & 0.07 & 0.08 & 0.08 \\
\hline Other & 0.03 & 0.02 & 0.02 & 0.01 & 0.02 & 0.01 & 0.02 & 0.02 & 0.02 & 0.01 \\
\hline \multicolumn{11}{|l|}{ Sector } \\
\hline Agriculture & & & 0.08 & 0.04 & 0.07 & 0.04 & 0.07 & 0.03 & 0.05 & 0.02 \\
\hline Industry & & & 0.51 & 0.41 & 0.52 & 0.40 & 0.49 & 0.38 & 0.48 & 0.38 \\
\hline Services & & & 0.42 & 0.55 & 0.41 & 0.56 & 0.44 & 0.59 & 0.47 & 0.60 \\
\hline \multicolumn{11}{|l|}{ Ownership } \\
\hline State & 0.81 & 0.69 & 0.88 & 0.83 & 0.77 & 0.71 & 0.62 & 0.59 & 0.40 & 0.37 \\
\hline Private & 0.08 & 0.07 & 0.10 & 0.12 & 0.17 & 0.23 & 0.26 & 0.30 & 0.43 & 0.45 \\
\hline Other & 0.10 & 0.23 & 0.01 & 0.03 & 0.01 & 0.02 & 0.01 & 0.02 & 0.01 & 0.02 \\
\hline $\begin{array}{l}\text { Household } \\
\text { members }\end{array}$ & 3.49 & 3.35 & 3.81 & 3.62 & 3.78 & 3.60 & 3.71 & 3.53 & 3.63 & 3.48 \\
\hline $\begin{array}{l}\text { Multi-generation } \\
\text { household }\end{array}$ & 0.13 & 0.08 & 0.22 & 0.16 & 0.24 & 0.19 & 0.24 & 0.19 & 0.24 & 0.20 \\
\hline Children $<18$ & 0.84 & 0.87 & 1.13 & 1.06 & 1.05 & 0.98 & 0.96 & 0.87 & 0.87 & 0.81 \\
\hline$n$ & 4934 & 4371 & 10671 & 8057 & 10202 & 7963 & 9097 & 7655 & 7224 & 6338 \\
\hline
\end{tabular}


${ }^{6}$ See Andrén and T. Andrén (2007) for a detailed description of the decomposition and each of its components.

${ }^{7}$ See Jacobs (1995) and Hansen and Wahlberg (2008) for details about occupational groups.

${ }^{8}$ We analyzed all cross-sections (1994-2000), but we report results for every second year. Unfortunately, although originally designed as a panel, the data do not permit linking of individual observations across all years.

Table 8 Descriptive statistics, female-dominated occupations

\begin{tabular}{|c|c|c|c|c|c|c|c|c|c|c|}
\hline & \multicolumn{2}{|l|}{$1960-89$} & \multicolumn{2}{|l|}{1994} & \multicolumn{2}{|l|}{1996} & \multicolumn{2}{|l|}{1998} & \multicolumn{2}{|l|}{2000} \\
\hline & Men & Women & Men & Women & Men & Women & Men & Women & Men & Women \\
\hline Wage $^{\#}$ & 1462.96 & 1388.34 & 141.99 & 127.22 & 311.25 & 276.84 & 926.18 & 841.49 & 2186.27 & 1885.4 \\
\hline Age & 29.80 & 25.90 & 40.82 & 38.37 & 39.90 & 38.64 & 39.94 & 38.86 & 40.27 & 39.86 \\
\hline \multicolumn{11}{|l|}{ Education } \\
\hline Lower education & 0.43 & 0.27 & 0.37 & 0.19 & 0.21 & 0.13 & 0.20 & 0.13 & 0.19 & 0.15 \\
\hline $\begin{array}{l}\text { Medium } \\
\text { education }\end{array}$ & 0.49 & 0.69 & 0.56 & 0.78 & 0.71 & 0.82 & 0.74 & 0.83 & 0.68 & 0.79 \\
\hline Higher education & 0.09 & 0.04 & 0.07 & 0.03 & 0.08 & 0.05 & 0.06 & 0.04 & 0.14 & 0.06 \\
\hline \multicolumn{11}{|l|}{ Region } \\
\hline R1: North-East & 0.17 & 0.13 & 0.16 & 0.12 & 0.14 & 0.11 & 0.15 & 0.11 & 0.13 & 0.12 \\
\hline R2: South-East & 0.12 & 0.12 & 0.12 & 0.13 & 0.13 & 0.13 & 0.12 & 0.14 & 0.12 & 0.12 \\
\hline R3: South & 0.15 & 0.14 & 0.19 & 0.15 & 0.12 & 0.14 & 0.12 & 0.14 & 0.14 & 0.15 \\
\hline R4: South-West & 0.12 & 0.09 & 0.12 & 0.10 & 0.13 & 0.09 & 0.13 & 0.09 & 0.10 & 0.09 \\
\hline R5: West & 0.13 & 0.11 & 0.08 & 0.11 & 0.10 & 0.12 & 0.12 & 0.12 & 0.15 & 0.11 \\
\hline R6: North-West & 0.11 & 0.11 & 0.12 & 0.13 & 0.14 & 0.14 & 0.17 & 0.15 & 0.14 & 0.15 \\
\hline R7: Center & 0.10 & 0.15 & 0.08 & 0.12 & 0.12 & 0.13 & 0.11 & 0.13 & 0.13 & 0.14 \\
\hline R8: Bucharest & 0.09 & 0.14 & 0.13 & 0.14 & 0.12 & 0.14 & 0.09 & 0.12 & 0.09 & 0.11 \\
\hline Married & 0.83 & 0.74 & 0.80 & 0.77 & 0.81 & 0.77 & 0.81 & 0.76 & 0.80 & 0.77 \\
\hline Urban & 0.65 & 0.79 & 0.65 & 0.80 & 0.63 & 0.77 & 0.63 & 0.77 & 0.70 & 0.80 \\
\hline \multicolumn{11}{|l|}{ Ethnicity } \\
\hline Romanian & 0.91 & 0.90 & 0.94 & 0.93 & 0.94 & 0.93 & 0.93 & 0.92 & 0.94 & 0.91 \\
\hline Hungarian & 0.07 & 0.09 & 0.04 & 0.06 & 0.04 & 0.06 & 0.04 & 0.07 & 0.06 & 0.08 \\
\hline Other & 0.02 & 0.02 & 0.02 & 0.01 & 0.02 & 0.01 & 0.03 & 0.01 & 0.01 & 0.01 \\
\hline \multicolumn{11}{|l|}{ Sector } \\
\hline Agriculture & & & 0.10 & 0.05 & 0.08 & 0.04 & 0.05 & 0.06 & 0.06 & 0.04 \\
\hline Industry & & & 0.21 & 0.27 & 0.19 & 0.25 & 0.19 & 0.24 & 0.16 & 0.22 \\
\hline Services & & & 0.69 & 0.68 & 0.73 & 0.71 & 0.76 & 0.70 & 0.79 & 0.73 \\
\hline \multicolumn{11}{|l|}{ Ownership } \\
\hline State & 0.83 & 0.81 & 0.87 & 0.86 & 0.81 & 0.77 & 0.69 & 0.68 & 0.50 & 0.47 \\
\hline Private & 0.10 & 0.11 & 0.09 & 0.10 & 0.14 & 0.17 & 0.23 & 0.23 & 0.32 & 0.33 \\
\hline Other & 0.06 & 0.06 & 0.02 & 0.02 & 0.02 & 0.02 & 0.02 & 0.02 & 0.01 & 0.01 \\
\hline $\begin{array}{l}\text { Household } \\
\text { members }\end{array}$ & 3.25 & 3.13 & 3.56 & 3.37 & 3.46 & 3.35 & 3.35 & 3.33 & 3.46 & 3.31 \\
\hline $\begin{array}{l}\text { Multi-generation } \\
\text { household }\end{array}$ & 0.12 & 0.12 & 0.20 & 0.16 & 0.20 & 0.18 & 0.20 & 0.17 & 0.20 & 0.16 \\
\hline Children $<18$ & 0.63 & 0.67 & 0.90 & 0.83 & 0.87 & 0.78 & 0.75 & 0.75 & 0.78 & 0.72 \\
\hline$n$ & 162 & 439 & 418 & 1491 & 391 & 1357 & 283 & 1157 & 309 & 1063 \\
\hline
\end{tabular}


Table 9 Wage equation estimates by occupation, women, 1960-2000

\begin{tabular}{|c|c|c|c|c|c|c|c|c|c|c|}
\hline & $1960-89$ & & 1994 & & 1996 & & 1998 & & 2000 & \\
\hline \multicolumn{11}{|l|}{ Male-dominated } \\
\hline Intercept & 5.783 & $* * *$ & 3.685 & $* * *$ & 3.925 & $* * *$ & 4.541 & $* * *$ & 5.102 & $* * *$ \\
\hline Age & 0.034 & & 0.114 & & 0.593 & $* * *$ & 0.480 & $* * *$ & 0.419 & * \\
\hline $\mathrm{Age}^{2} / 10$ & -0.009 & & -0.013 & & -0.080 & $* * *$ & -0.054 & $* *$ & -0.044 & \\
\hline Medium education & -0.144 & & -0.068 & & -0.114 & $* *$ & -0.133 & $* *$ & -0.093 & \\
\hline Higher education & 0.318 & $* * *$ & 0.522 & $* * *$ & 0.527 & $* * *$ & 0.511 & $* * *$ & 0.762 & $* * *$ \\
\hline Married & 0.049 & & 0.015 & & -0.014 & & -0.027 & & -0.131 & ** \\
\hline Urban & 0.095 & $* *$ & 0.069 & $* *$ & 0.155 & $* * *$ & 0.048 & & 0.036 & \\
\hline Agriculture & 0.265 & $* * *$ & -0.049 & & -0.024 & & -0.112 & & -0.142 & \\
\hline Industry & -0.032 & & 0.085 & & 0.146 & $* * *$ & 0.070 & & 0.219 & $* * *$ \\
\hline State ownership & -0.032 & & 0.046 & & 0.064 & * & -0.007 & & -0.029 & \\
\hline Long-term contract & -0.001 & & 0.275 & $* * *$ & 0.038 & & 0.175 & & 0.447 & $* * *$ \\
\hline Multi-generation household & 0.040 & & -0.107 & $* *$ & -0.121 & $* *$ & -0.121 & $* *$ & -0.198 & $* * *$ \\
\hline Household members & & & 0.008 & & -0.017 & & -0.003 & & 0.006 & \\
\hline \multicolumn{11}{|l|}{ Integrated } \\
\hline Intercept & 5.213 & $* * *$ & 3.946 & $* * *$ & 4.451 & $* * *$ & 5.118 & $* * *$ & 6.134 & $* * *$ \\
\hline Age & 0.090 & & 0.189 & $* * *$ & 0.255 & $* * *$ & 0.268 & $* * *$ & 0.179 & $* * *$ \\
\hline $\mathrm{Age}^{2} / 10$ & -0.022 & * & -0.019 & $* * *$ & -0.026 & $* * *$ & -0.024 & $* * *$ & -0.012 & * \\
\hline Medium education & 0.001 & & 0.024 & * & 0.029 & $* *$ & 0.045 & $* * *$ & 0.021 & \\
\hline Higher education & 0.363 & $* * *$ & 0.479 & $* * *$ & 0.522 & $* * *$ & 0.522 & $* * *$ & 0.532 & $* * *$ \\
\hline Married & 0.019 & & 0.001 & & 0.010 & & 0.007 & & -0.007 & \\
\hline Urban & 0.267 & $* * *$ & 0.107 & $* * *$ & 0.130 & $* * *$ & 0.117 & $* * *$ & 0.095 & $* * *$ \\
\hline Agriculture & -0.056 & & 0.103 & $* *$ & 0.088 & $* *$ & 0.078 & $* *$ & 0.106 & ** \\
\hline Industry & -0.116 & * & 0.067 & & 0.036 & & 0.100 & $* * *$ & 0.084 & * \\
\hline State ownership & & & 0.000 & & 0.043 & & -0.057 & * & -0.024 & \\
\hline Long-term contract & & & 0.064 & $* *$ & 0.221 & $* * *$ & 0.169 & $* * *$ & 0.164 & $* * *$ \\
\hline \multicolumn{11}{|l|}{ Multi-generation household } \\
\hline Household members & -0.005 & & -0.015 & $* * *$ & -0.018 & $* * *$ & -0.016 & $* * *$ & -0.032 & $* * *$ \\
\hline \multicolumn{11}{|l|}{ Female-dominated } \\
\hline Intercept & 6.911 & $* * *$ & 4.947 & $* * *$ & 5.359 & $* * *$ & 6.038 & $* * *$ & 6.577 & $* * *$ \\
\hline Age & 0.211 & & 0.151 & & 0.285 & $* * *$ & 0.285 & $* *$ & 0.300 & $* *$ \\
\hline $\mathrm{Age}^{2} / 10$ & -0.026 & & -0.016 & & -0.030 & $* *$ & -0.029 & * & -0.029 & * \\
\hline Medium education & -0.216 & $* * *$ & -0.135 & $* * *$ & -0.145 & $* * *$ & -0.070 & * & -0.020 & \\
\hline Higher education & 0.319 & $* * *$ & 0.207 & $* * *$ & 0.278 & $* * *$ & 0.212 & $* * *$ & 0.255 & $* * *$ \\
\hline Married & -0.069 & & -0.033 & & -0.069 & $* *$ & -0.038 & & 0.000 & \\
\hline Urban & 0.054 & & 0.119 & $* * *$ & 0.114 & $* * *$ & 0.062 & $* *$ & 0.076 & ** \\
\hline Agriculture & 0.121 & $* *$ & 0.191 & $* * *$ & 0.262 & $* * *$ & 0.055 & & 0.020 & \\
\hline Industry & 0.113 & $* * *$ & 0.246 & $* * *$ & 0.198 & $* * *$ & 0.127 & $* * *$ & 0.119 & $* * *$ \\
\hline State ownership & 0.001 & & 0.005 & & -0.052 & $* *$ & -0.008 & & -0.008 & \\
\hline Long-term contract & 0.025 & & 0.082 & & 0.092 & & -0.013 & & 0.234 & ** \\
\hline Multi-generation household & 0.081 & & -0.089 & $* *$ & -0.124 & $* * *$ & -0.074 & * & -0.044 & \\
\hline Household members & & & 0.013 & & 0.003 & & -0.024 & $* *$ & -0.015 & \\
\hline
\end{tabular}

Note: we also control for region (5 dummies), ownership ( 3 dummies), and "time" ( 5 dummies controlling for the fiveyear periods for the communist period, and 11 monthly dummies for the transition years). This note holds also for the next table. 
Table 10 Wage equation estimates by occupation, men, 1960-2000

\begin{tabular}{|c|c|c|c|c|c|c|c|c|c|c|}
\hline & $1960-89$ & & 1994 & & 1996 & & 1998 & & 2000 & \\
\hline \multicolumn{11}{|l|}{ Male-dominated } \\
\hline Intercept & 6.264 & $* * *$ & 3.887 & $* * *$ & 4.126 & $* * *$ & 5.560 & $* * *$ & 7.054 & $* * *$ \\
\hline Age & 0.146 & & 0.283 & $* * *$ & 0.404 & $* * *$ & 0.068 & & 0.315 & $* * *$ \\
\hline $\mathrm{Age}^{2} / 10$ & -0.016 & & -0.035 & $* * *$ & -0.049 & $* * *$ & -0.006 & & -0.033 & $* * *$ \\
\hline Medium education & 0.026 & & 0.001 & & 0.008 & & 0.006 & & 0.198 & $* * *$ \\
\hline Higher education & 0.357 & $* * *$ & 0.409 & $* * *$ & 0.409 & $* * *$ & 0.438 & $* * *$ & 0.829 & $* * *$ \\
\hline Married & -0.031 & & 0.076 & $* * *$ & 0.116 & $* * *$ & 0.166 & $* * *$ & 0.048 & \\
\hline Urban & 0.072 & $* * *$ & 0.094 & $* * *$ & 0.141 & $* * *$ & 0.091 & $* * *$ & 0.127 & $* * *$ \\
\hline Agriculture & 0.060 & * & -0.118 & $* * *$ & -0.100 & $* * *$ & -0.104 & $* * *$ & -0.428 & $* * *$ \\
\hline Industry & 0.054 & & 0.003 & & 0.036 & $* *$ & 0.050 & $* * *$ & 0.138 & $* * *$ \\
\hline State ownership & -0.058 & & 0.028 & & 0.078 & $* * *$ & 0.127 & $* * *$ & 0.107 & $* * *$ \\
\hline Long-term contract & 0.002 & & 0.144 & $* * *$ & 0.128 & $* * *$ & 0.074 & & 0.082 & \\
\hline Multi-generation household & -0.011 & & -0.073 & $* * *$ & -0.073 & $* * *$ & -0.091 & $* * *$ & -0.029 & \\
\hline Household members & & & -0.003 & & -0.010 & * & -0.015 & $* *$ & -0.008 & \\
\hline \multicolumn{11}{|l|}{ Integrated } \\
\hline Intercept & 5.702 & $* * *$ & 4.231 & $* * *$ & 4.762 & $* * *$ & 5.451 & $* * *$ & 5.993 & $* * *$ \\
\hline Age & 0.038 & & 0.281 & $* * *$ & 0.310 & $* * *$ & 0.326 & $* * *$ & 0.314 & $* * *$ \\
\hline $\mathrm{Age}^{2} / 10$ & -0.003 & & -0.034 & $* * *$ & -0.036 & $* * *$ & -0.037 & $* * *$ & -0.031 & $* * *$ \\
\hline Medium education & 0.059 & $* * *$ & -0.002 & & -0.004 & & 0.025 & $* *$ & 0.116 & $* * *$ \\
\hline Higher education & 0.285 & $* * *$ & 0.309 & $* * *$ & 0.347 & $* * *$ & 0.373 & $* * *$ & 0.466 & $* * *$ \\
\hline Married & 0.020 & & 0.079 & $* * *$ & 0.083 & $* * *$ & 0.122 & $* * *$ & 0.088 & $* * *$ \\
\hline Urban & 0.165 & $* * *$ & 0.099 & $* * *$ & 0.120 & $* * *$ & 0.123 & $* * *$ & 0.117 & $* * *$ \\
\hline Agriculture & 0.376 & $* * *$ & -0.005 & & -0.007 & & -0.088 & $* * *$ & -0.199 & $* * *$ \\
\hline Industry & 0.081 & $* * *$ & 0.081 & $* * *$ & 0.130 & $* * *$ & 0.124 & $* * *$ & 0.134 & $* * *$ \\
\hline State ownership & -0.014 & & 0.050 & $* * *$ & 0.069 & $* * *$ & 0.076 & $* * *$ & 0.062 & $* * *$ \\
\hline Long-term contract & 0.006 & & 0.070 & $* * *$ & 0.159 & $* * *$ & 0.154 & $* * *$ & 0.157 & $* * *$ \\
\hline Multi-generation household & 0.002 & & -0.085 & $* * *$ & -0.096 & $* * *$ & -0.077 & $* * *$ & -0.109 & $* * *$ \\
\hline Household members & & & -0.011 & $* * *$ & -0.006 & * & -0.010 & $* * *$ & -0.002 & \\
\hline \multicolumn{11}{|l|}{ Female-dominated } \\
\hline Intercept & 5.417 & $* * *$ & 4.374 & $* * *$ & 4.731 & $* * *$ & 5.501 & $* * *$ & 5.909 & $* * *$ \\
\hline Age & 0.596 & $* *$ & 0.462 & $* * *$ & 0.553 & $* * *$ & 0.387 & & -0.166 & \\
\hline $\mathrm{Age}^{2} / 10$ & -0.068 & * & -0.055 & $* * *$ & -0.060 & $* * *$ & -0.044 & & 0.027 & \\
\hline Medium education & 0.131 & * & -0.114 & $* * *$ & -0.119 & $* *$ & -0.102 & & 0.111 & $*$ \\
\hline Higher education & 0.269 & $* *$ & 0.121 & & 0.087 & & 0.282 & $* *$ & 0.337 & $* * *$ \\
\hline Married & -0.111 & & 0.080 & & 0.156 & $* *$ & 0.014 & & 0.161 & $* *$ \\
\hline Urban & 0.256 & $* * *$ & 0.187 & $* * *$ & 0.176 & $* * *$ & 0.043 & & 0.083 & \\
\hline Agriculture & 0.043 & & 0.184 & $* *$ & -0.001 & & -0.096 & & -0.280 & $* * *$ \\
\hline Industry & -0.120 & & 0.072 & & 0.104 & & 0.046 & & 0.073 & \\
\hline State ownership & -0.159 & & 0.050 & & -0.030 & & -0.026 & & 0.099 & $* *$ \\
\hline Long-term contract & 0.065 & $* *$ & 0.170 & & -0.022 & & -0.013 & & -0.094 & \\
\hline Multi-generation household & -0.254 & * & -0.070 & & 0.028 & & -0.170 & $* *$ & 0.004 & \\
\hline Household members & & & -0.020 & & -0.039 & $* *$ & -0.016 & & 0.009 & \\
\hline
\end{tabular}


${ }^{9}$ See Jacobs (1995) for details about occupational groups.

${ }^{10}$ The distribution of individuals across these three groups was almost the same when we chose another cutting point (e.g., 25\%,30\%, 35\%). Figure 3 shows the evolution of these groups during 1951-2000. We divide the period before 1990's into 5-year periods that overlap five-year development plans. Tables 6, 7 and 8 present basic descriptive statistics (by gender) for some variables used in the empirical analysis.

${ }^{11}$ See Andrén (2012) for a detailed description and analysis of wage differences between ethnic Romanians and ethnic Hungarians.

${ }^{12}$ Tables 9 and 10 present the estimates of domain-specific (i.e., MD, GI and FD) wage equations for men and women respectively.

${ }^{13}$ However, a non-zero effect could also be due to lack of controlling for relevant variables.

Competing interests

The IZA Journal of European Labor Studies is committed to the IZA Guiding Principles of Research Integrity. The authors declares that they have observed these principles.

\section{Acknowledgements}

We thank the editor and anonymous referees for helpful and relevant comments. Financial support from The Swedish Research Council is gratefully acknowledged. The usual disclaimer applies.

Responsible editor: Alan Barrett

\section{Author details}

${ }^{1}$ Örebro University School of Business, Örebro SE-701 82, Sweden. ${ }^{2}$ Swedish Confederation of Professional Associations (Saco), Stockholm SE-103 15, Sweden.

Received: 24 September 2014 Accepted: 12 February 2015

Published online: 15 May 2015

\section{References}

Andrén D (2012) Romanians, Hungarians and their wages, in transition, in Romania. Econ Model 29(6):2673-85 Andrén D and Andrén T (2007) Occupational gender composition and wages in Romania: from planned equality to market inequality. Working Papers in Economics 261, Department of Economics, School of Business, Economics and Law at Göteborg University, Gothenburg, Sweden

Atkinson AB, Micklewright J (1992) Economic Transformation in Eastern Europe and the Distribution of Income. Cambridge Univ, Press, Cambridge, UK

Becker $G(1957,1971)$ The Economics of Discrimination, 2nd edn. The University of Chicago Press, Chicago

Becker G (1985) Human capital, effort, and the sexual division of labor. J Labor Econ 3:553-58

Borjas GJ (1992) Ethnic Capital and Intergenerational Mobility. Q J Econ 107(1):123-50

Borjas GJ (1995) Ethnicity, neighborhoods, and human-capital externalities. Am Econ Rev 85(3):365-90

Brainerd E (1998) Winners and Losers in Russia's Economic Transition. Am Econ Rev 88:1094-1115

Brainerd E (2000) Women in Transition: Changes in Gender Wage Differentials in Eastern Europe and the Former Soviet Union. Ind Labor Relat Rev 54(1):138-62

Earle J, Sapatoru D (1993) Privatization in a Hypercentralized Economy. In: Earle J, Frydman R, Rapaczynski A (eds) Privatization in the Transition to a Market Economy: Studies of Preconditions and Policies in Eastern Europe. Pinter and St. Martin's Press, London

England P, Farkas G, Kilbourne BS, Dou T (1988) Explaining Occupational Sex Segregation and Wages: Findings from a Model with Fixed Effects. Am Sociol Rev 53:544-58

Giddings L (2002) Changes in Gender Wage Differentials in Bulgaria's Transition from Plan to Mixed Market. East Econ J 28(4):481-98

Gunderson M (1989) Male-female Wage Differentials and Policy Responses. J Econ Lit 27(1):46-72

Ham J, Svejnar J, Terrell K (1995) "Unemployment, Restructuring, and the Labor Market in Eastern Europe and Russia: Czech Republic and Slovakia," in Commander S, Coricelli F, eds. Unemployment, Restructuring, and the Labor Market in Eastern Europe and Russia. Washington, D.C: Economic Development Institute of the World Bank

Hansen J, Wahlberg R (2008) Occupational Gender Composition and the Gender Wage Gap in Sweden. Res Labor Econ 28:353-69

Hunt J (2002) The transition in East Germany: when is a ten-point fall in the gender gap bad news? J Labor Econ 20(1):148-69

Jacobs SC (1995) Changing Patterns of Sex Segregated Occupations throughout the Life-Course. Eur Sociol Rev 11(2):157-71

Jurajda Š (2003) Gender wage gap and segregation in enterprises and the public sector in late transition countries. J Comp Econ 31(2):199-222 
Jurajda Š (2005) Gender segregation and wage gap: An East-west comparison. J Eur Econ Assoc 3(2-3):598-607 Jurajda S, Harmgart H (2007) When are 'Female' Occupations Paying More? J Comp Econ 35(1):170-87

Katz K (1994) Gender Differentiation and Discrimination: A Study of Soviet Wages. Göteborgs Universitet, Sweden, Doctoral dissertation

Katz K (1997) Gender, Wages, and Discrimination in the USSR: A Study of a Russian Industrial Town. Camb J Econ 21(4):431-52

Lehrer EL (2004) The Role of Religion in Union Formation: An Economic Perspective. Popul Res Policy Rev 23:161-85 Macpherson DA, Hirsch BT (1995) Wages and Gender Composition: Why Do Women's Jobs Pay Less? J Labor Econ 13:426-71

Münich D, Svejnar J, Terrell K (2005) Returns to Human Capital under the Communist Wage Grid and during the Transition to a Market Economy. Review of Economics and Statistics 87(1): 100-283

National Commission for Statistics. 1995. Romanian Statistical Yearbook 1994, p. 272-3.

Ogloblin CG (1999) The gender earnings differential in the Russian transition economy. Ind Labor Relat Rev 52(4):602-27

Orazem PF, Vodopivec M (2000) Male-female differences in labor market outcomes during the early transition to market: The cases of Estonia and Slovenia. J Popul Econ 13(2):283-303

Newell A, Reilly B (1996) The gender wage gap in Russia: some empirical evidence. Labour Econ 3(3):337-56

Newell A, Reilly B (2000) The gender wage gap in the transition from Communism: some empirical evidence. Working paper No. 305, William Davidson Institute, Ann Arbor, MI

Paternostro S, Sahn D (1999) Wage Determination and Gender Discrimination in a Transition Economy: The Case of Romania. World Bank Policy Research Working Papers, 2113, World Bank, Washington

Roy A (1951) Some thoughts on the distribution of earnings. Oxf Econ Pap 3:135-46

Skoufias E (2003) The Structure of Wages during the Economic Transition in Romania. Econ Syst 27(4):345-66

Sorensen E (1989) Measuring the Pay Disparity Between Typically Female Occupations and Other Jobs: A Bivariate Selectivity Approach. Ind Labor Relat Rev 42(4):624-39

Sorensen E (1990) The Crowding Hypothesis and Comparable Worth Issue: A Survey and New Results. J Hum Resour 25:55-89

UNESCO (2002) Literacy and Non Formal Education Section, Estimated illiteracy rate and illiterate population aged 15 and older by country, 1970-2015, UESCO Institute for Statistics, July 2002 Assessment

\section{Submit your manuscript to a SpringerOpen ${ }^{\circ}$ journal and benefit from:}

- Convenient online submission

- Rigorous peer review

- Immediate publication on acceptance

- Open access: articles freely available online

- High visibility within the field

- Retaining the copyright to your article 